\title{
The Study of Leap-forward and Sustainable Development in Chinese Cashmere Industry
}

\author{
Yuanyuan $\mathrm{Li}$ \\ School of International Business, Inner Mongolia University of Technology \\ Jin Chuan campus of Inner Mongolia University of Technology \\ Hohhot 010080, Inner Mongolia, China \\ Tel: 86-471-496-9847Ｅ-mail: hushiliyuanyuan@126.com
}

Received: January 13, 2011 Accepted: January 30, $2011 \quad$ doi:10.5539/ass.v7n6p136

The research is financed by the foundation of Inner Mongolia University of Technology social and scientific program (Grant No.SK201034).

\begin{abstract}
Although the haze of world financial crisis is fading, the caution from the crisis is still keeping the red light on to Chinese Cashmere industry. So, this paper after retrospective analysis of the main reasons of crisis triggered cashmere industry predicament by taking the Inner Monongalia cashmere industry as an example, find that: it is of the great significance for Chinese cashmere industry to achieve leap-forward and sustainable development during the crucial period at present. To reexamine the problem of development in a new view, we need to adjust cashmere industry developing thoughts through taking full advantage of opportunities afforded by the post-financial crisis era, and to achieve the purpose of cashmere industry development based of dynamic comparative advantage. Further more, putting forward suggestions on realizing leap-forward sustainable development, expecting to handle appropriately the relationship between the development of Chinese cashmere industry and the population, resources and environment, and keep harmony with natural resources and environment.
\end{abstract}

Keywords: Cashmere industry, Industry predicament, Inner Monongalia, Leap-forward and sustainable development

Although the haze of world financial crisis is fading, the caution from the crisis is still keeping the red light on to Chinese cashmere industry. The financial crisis has led to the international market of Chinese cashmere industry shrink. The appreciation of the RMB, higher labor prices, energy and commodities prices make the production cost rise dramatically. These will have impacts on the cashmere enterprises which depend more highly on export. To reexamine the problem of development in a new view, we need to adjust cashmere industry developing thoughts through taking full advantage of opportunities afforded by the post-financial crisis era, and to achieve the purpose of cashmere industry development based of dynamic comparative advantage. The worldwide cashmere industry is comprised of $60 \%$ production from China, 30\%from Mongolia, and the remainder from Afghanistan and Iran. China's provinces of Inner Mongolia and Hubei produce $80 \%$ of Chinese cashmere and $20 \%$ of the world's supply of raw cashmere, with advantages in access to international capital markets. King Deer and Erdos are two of the dominant brands, with the former producing 1,600 tons of raw de-haired cashmere, or two million cashmere sweaters, in 2001 and according to World Bank reports. As one of the largest pastoral areas in China, Inner Mongolia cashmere production occupies the first place. The cashmere industry is one of the important Inner Mongolia export business lines of earning foreign exchange. But, in 2008, export volume of cashmere sweater and woolen sweater is 545.9 million, reduced 280 million or declining as much as $33.84 \%$ over the same period of the previous year, affected by RMB appreciation and the global financial crisis. According to statistics of the Inner Mongolia entry-exit inspection and quarantine Bureau, the exports to Japan and America, fell to 56.3 and $31.8 \%$ respectively in 2008 .

\section{The Retrospective Analysis of Main Reasons of Crisis Triggered by Cashmere Industry Predicament}

\subsection{The moderate tight finance monetary policy}

In order to take active steps to effectively tackle the financial crisis, the Chinese government adopted the moderate tight monetary policy. The cashmere industry relies on overseas to a considerable extent, poor products 
mobility puts more pressures on storage, so the enterprises generally have the problems of insufficient own funds and difficulties in funds flow. For more risk considerations management of bank loans, more strict vetting criteria are required, so enterprises difficult to obtain bank loan. It has become a common practice that just because the financial crisis causes the bank to pity the loan, so many cashmere enterprises fall into the financing difficult position. At the same time, business investment willingness and ability to drop.

\subsection{The Increasing of Latent Risks in the Financial Sectors}

Because the cashmere industry is an export-oriented industry, cashmere product competition in foreign trade has affected strongly with the RMB against the U. S. dollar passive appreciation. More rapid growth of the monetary base raises the growth rate of nominal money supply, leading to inflation if nothing else changes. It will increase the latent risks in the financial sectors to the cashmere firms. Exchange loss can not be avoided during the process of RMB revaluation. China is a manufacturing country and makes the cashmere manufacturing sectors of the profits, but the revaluation of the RMB has engulfed a lot of profits, even some business at a loss. The enterprises are forced to raise their offer constantly and their export sales growth rate has dropped significantly.

\subsection{Insufficient Market Demands, Sharp Reduction in International Demands}

The global economic slowdown results in Chinese products a sharp reduction in external demands, the export growth fell significantly. The western countries reduce buying high-grade product as a belt-tightening measure amid the crisis, so the appearance of insufficient demands is the fall in volume of exports of China Cashmere in a certain extent.

The United States sub-loan crisis of the global economic recession and decline in external demands, cashmere enterprise exports of the negative effects become more and more strong, which is directly represented in significant dropping of trade America growth rate. In addition, affected by American, European and Japanese markets markedly declined demands, a sharp drop in new orders of Cashmere products, especially from abroad. Since 2008, exports to the United States keeps in a decline situation in the same period last year. According to the Entry and Exit Inspection and Quarantine Bureau statistic, in this period, the decline of export mostly from cashmere sweater products in Inner Mongolia, which is one of biggest Cashmere export centers in China. Especially, the business of export to Japan and the U.S.A. has decreased most, as much as 56.3 and 31.8 percent decline respectively.

\subsection{The Operator and Consumer in the Pessimistic Expectations to the World Economic}

Prospect theory is a decision theory of great influence on psychics and economics. The rational anticipated school arises to go up at sluggish of economy of 1970s in the United States. According to the theories, anticipation mainly refers to consumers and enterprises estimated values to the economic variables in a period of time in the future. The anticipation is divided into three types by John. Muth: first is static anticipation, the second is extrapolation anticipation, the third is suitability anticipation. But it is now generally believed that: static anticipation $y_{t}^{e}=y_{t-1}$, suitability anticipation $y_{t}^{e}=\alpha y_{t-1}(1-\alpha) y_{t-1}^{e}$ and Rational Expectation $y_{t}^{e}=E\left(y_{t} \mid I_{t-1}\right)$, that are truly trust three kinks of different anticipation concepts of this school, in which $I_{t-1}=\left\{y_{t-1}, y_{t-2}, \ldots, y_{1}\right\}$ is mastered ensemble of communication in t-1 stage. According to current theories, affected by the uncertain economic development trend of uncertainty and market prospect, business confidence, investment to expand a serious loss to the world economy weakened, static, lack of pessimism rational expectations, the biggest influence on fluff industry is the amount of orders. The export growth rate of Inner Mongolia main cashmere products have been gradually decreasing since 2003 .

To the consumers, because of the risk of greater uncertainty and the fall income, they tend to choose the relative inexpensive commodities to satisfy the need of fashion and warm. Consumption in a depressed state has precluded sellers from being able to determine sales plan in America and Europe developed countries. The cashmere products dealers can not determine the sales plan, thus reduce import orders. In the other hand, the cashmere enterprise's confidence has also dropped to the bottom, the will of expansion and investment are weakened. The pessimistic expectations on the economy and lack of Rational Expectation, its biggest impact is on orders for cashmere products plunged. Thus any falloff in demand for imports is usually accompanied by a drop in export orders.

\subsection{The Status of Recession on Downstream Industry Chain}

The cashmere price has fallen to lowermost limit this year. It is a hard hit in the enthusiasm of raising goats to the herdsman. Due to a generally dismal climate for international textile industry, sharp drop in cashmere products exports directly result in declining prices of original cashmere. The price of finished cashmere has fallen from 65.5 thousand Yuan for each ton in 2006 and 65 thousand Yuan in 2007 to 55 thousand Yuan more or 
less in 2008. As the past law of "buy or not to buy up", the lower the price, the less consumer demands. The process can feed on itself: Consumers and businesses delay spending, leading to a worse downturn. Against this backdrop, cashmere prices will fall further and the problem of difficult to sell is very outstanding.

\section{The Significance of leap-forward and Sustainable Development in Chinese Cashmere Industry}

\subsection{The Meaning of Leap-forward Sustainable Development}

Leap-forward sustainable development mainly includes two aspects: one is to use the human co-creation civilization sufficiently in a relatively short period of time, less links and less cost, skipping what the developed countries have experienced and some needless repetition processes, in order to form advantage of backwardness and achieve the same target, which the developed countries was passed the development course, that is, in each stage of development is rapidly, eventually catch up with the developed countries. The other meaning is the leap-forward development, just a kind of sustainable development mode.

\subsection{The Theoretical Basis of Leap-forward Development}

The Quantum theory is that the form of movement can be continuous wave, also can be in the form of discrete particle. This kind of discrete form is often a leap, that is to say, the form of movement contains leaping. We see how probability, the wave-particle duality, and the indivisibility of quantum transfers are all related. "The division of labor and comparative operation costs" theory: underdeveloped countries and regions, because of direct absorption and introducing advanced technology from developed countries and regions, the cost is much less than the initial explored countries. In the same conditions of capital resources, technology and cost, as the labor cost better than for the developed, if only under the protection of the state, to attain the economies of scale stage, that new industries can be developed, thus to catch up or exceed the advanced countries or regions to realize the great-leap-forward development in the traditional capital or technology-intensive areas within the division.

\subsection{The Great Significance}

At present, the Chinese cashmere is in the post-financial Crisis Era and still affected by this special period. There are five features of economic trend in the Post-financial Crisis Era:

The first, the world is likely to see a dramatic change in consumption and savings structure, American consumption rate continues to decrease and saving rate keeps increasing. The market will be more narrowly and competition more intense. According to Chinese customs statistics, Chinese cashmere products export total 92563 million US dollars with a comparative growth rate of $23.2 \%$ in the first nine months in 2010 . The cashmere and dehaired wool exports reached 1901 tons, amounted 14116 million dollars, up $44 \%$ and $64 \%$ respectively growth, Cashmere products 78447 million us dollars, up 7.9\% growth over the same period of the previous year. Specifically speaking, cashmere yarn exports 2837 tons, amount 23779 million US dollars, respectively growth of $22 \%$ and $44.8 \%$ over the same period of the previous year; Cashmere scarf 8162 million US dollars, up15.3 percent growth, Cashmere 43040 million US dollars, growth of 7\%. In the first half of 2010, a remarkable characteristic of cashmere industry is the raw material prices running in high prices, but the end products sales price does not appear corresponding amplitude adjustment and cashmere deep processing enterprises' profits does not keep the synchronous growth pace with value of export. The export growth is expected to fall back in a certain degree in the next half of 2010. Therefore, Chinese cashmere enterprises should do more than a good external market and how to develop the domestic market well which also needs many Chinese enterprises transformation to deal with.

The second, due to financial bubble burst, the global economy will return to develop industry. It is a challenge for Chinese enterprise from developed countries to develop industry, too, thus the race of cashmere industry will be more competitive.

The third, low-carbon economy will become a new growth point, new technology and new market occupation will provide many opportunities to enterprises. Likewise, cashmere enterprises will be also facing new challenges, such as learning new knowledge and new technology.

The forth, emerging markets will be the world largest market. Emerging markets which itself has taken up around $40 \%$ of the world's economy, the proportion will ascend to over $50 \%$ in the post-financial crisis era. China cashmere enterprises need to pay more attention to Southeast Asia, South America and other emerging markets. At the same time, with the growth of these economic entities, they are competing more fiercely with their Chinese counterparts for market.

The last, looking on the financial crisis as a watershed, transnational development of Chinese enterprises is an 
inexorable trend. But transnational development requires more knowledge advanced technologies, including political, legal, economic, cultural, religious and other aspects. From this, how to enhance comprehensive strength rapidly and to make effective learning enterprises is the key to win the drastic competition. Many native cashmere enterprises have captured the information cutely, and committed to improve learning ability and development.

Through the above analysis, our country's cashmere industry leap-forward and sustainable development is of great significant in the Post-financial Crisis Era. The leap-forward and sustainable development is also a supernormal development mode adopted to better meet the needs of economic and social development. The essence is to be guided by theories of sustainable development theory, to conduct cashmere industry structure optimization for the main way, to act management innovation and technological innovation as a driving force, to accelerate transform the traditional cashmere industry to the modern, to narrow the gap with the developed countries, to have the cashmere industry enter on sustainable development of the new stage at an early date.

\section{The Suggestions on Realizing Leap-forward Sustainable Development of Cashmere Industry}

\subsection{Rising Risk Consciousness of Exchange Rate, Actively Analyzing of International Financial Market Trends}

The essential difference between strategic and nonstrategic decisions is that the latter can be made in "isolation", without taking into account the decisions that others might take. Obviously, Chinese cashmere industry should take the former, rise risk consciousness of exchange rate and actively analyze international financial market trends. In operating process, to continuously improve the abilities of using various effective risk Circumvention tools for the exchange rate, pay close attention to the price changes of RMB exchange rate, budget the factors of exchange rate in advance, try to valuate and settle in a variety of currencies as signing contracts with foreign firms, in case there would be great change on the exchange rate of dollar and euro, select the appropriate other currency to settle. When signing export contracts, as far as possible choose the currency in an uptrend to valuate, while the import contract signed is on the contrary. To establish long-term cooperation relationship with business partners by the way of shorten the time limit or concluding the aging and short contracts, in order to keep away from the floating risk.

\subsection{Establishing Rational Anticipate, Positively Guiding from the Macro and Micro Level}

In recent two years, the new trend of domestic economic operation and the economic policy undoubtedly affect people's estimate and judgment to the future society, economy and life. Uncertainty about the expectations of firms and consumers is one reason that policy-makers can go wrong in using active stabilization policy. Although Chinese government adopted the proactive fiscal policy and monetary policy in order to stimulate consumption, boost domestic demands, the consumers and enterprises' pessimistic expectations, offset by the Chinese government's series of macroeconomic policies favorable effect to a certain extent, make domestic consumption "opened and immobile" instead. It is necessary to guide in positive and effective way from the macro and micro levels, establish economic rational expectations. The government should establish harmonious relationship with microeconomic entities, win the trust of the people, narrow the deviation between the policy change and market expectations, reduce unfair intervention of the government's decision at all levels to cashmere industry, provide stable policy anticipation, establish the dynamic cooperation and game characterized by mutual benefit and reciprocity, use a broad mix of policy tools to increase the strength and depth of regulation, to establish firm faith from the source of the cashmere industry chain to the terminal in each aspect.

\subsection{Reducing Market Pressure, Changing the Situation of Centralized Export Market and Keeping Domestic and} Export Increase in the Same Pace

Because the cashmere product belongs to top grade products with the greater market demand flexibility, under the background of economic uncertainty, the life circle of product purchasing comes to be prolonged. With a looming global financial crisis aggravating the difficulties posed by a fierce market, some of the strength poor enterprises and brands have been eliminated. Increasing the reasonable consumption awareness, good reputation and quality products have enjoyed growing favor, so market advantages, market share is adequate to good corporate brands. Faced with this situation, cashmere enterprises need to recognize domestic cashmere industry trends, understand consumer needs, so that their products can meet the changing market demands. In the stability of the existing Europe, America and Japan markets, to explore the new high-end products actively, especially for the emerging economies which are equipped to bounce back from the crisis faster, also have the vast potential demands and consumption ability, must be one of the leading forces to pull up cashmere exported. And industry association should play an active role for cashmere enterprises supplying overseas information. 
At the same time, cashmere enterprises should actively expand the domestic market. China is the world's fourth-largest economy entity, but consumer spending is less than $40 \%$ of GDP, and other larger economies are $65 \%$. Though demand growth has slackened as its economic growth as slowed, still faces long-term demand issues in China. Swedish economist, Gustav Cassel, was the first to formally and systematically put forward purchasing power parity theory. According to the PPP theory proposed, Chinese families with average income should reach $\$ 21000$ to $\$ 29000$. This figure is more accurate to show the real income and purchasing level of such group. Although the consumption level of middle-income families is still lower than the developed country's, it will apply a more space to buy high-grade cashmere freely in China. The consumer is not only concerned about the quality, but also made higher demands for cashmeres products. Enterprises should carry detailed market research to understand the changes in consumer demand, and actively provide better products to meet the consumers' demands.

\subsection{Increasing Innovation Investment, Realizing the Green Environmental Protection and Improving the Quality of the Product}

To the development problem, above all, must handle appropriately the relationship between Chinese cashmere industry and population, resources and environment, must have industry growth adapt with our country socialism productivity level and must keep harmony with natural resources and environment. So, eliminating the negative impacts on the crisis, the innovation investment should be increased significantly, new energy, new materials, information and biological technology as the core of the new scientific and technological revolution will lead cashmere industry into the green, intelligent and sustainable development of new age. Strengthen products innovation has become necessary to survival and develop in the post-financial crisis and focus on the products' functionality, fashion, scientific and technological aspects to meet different needs of consumers. Meanwhile, the trend of economic globalization has irreversible, international division of labor and cooperation will further strengthen, industry and market integration and common development will speed up. In this background, cashmere enterprises should further change management concept and mode, improve the ability of independent innovation, develop high-tech, functional differentiation and green environmental protection fibers, encourage and support enterprises in the wider use of new technologies, new processes and new equipment of fiber, energy conservation and emission reduction of new technology, new technology, new equipment, further backward productivity, reduce use of outdated capacity, open up cooperation in the downstream industry chain and form a complete industrial chain, promote the market competitiveness.

\section{Conclusion}

Leap-forward and sustainable development in cashmere industry is of the great significance in the post-financial crisis era at present. We should initiatively grasp the development opportunities firmly in order to impel Chinese Cashmere industry to develop in profound change's international economic environment. Only adopt of various measures to deal with the financial crisis by taking full advantage of opportunities afforded by the post-financial crisis era, based on the proper relationship between cashmere industry and the population, resources and environment, the sustainable aim can be realize, can achieve the purpose of leap-forward and sustainable development in cashmere industry ultimately.

\section{References}

China statistical yearbook of 2004-2009. China statistics press David Bohm. (1989). Quantum Theory. The United States of America Dover Publications. 141-143.

Chu, Xiao. (2003). Study on sustained development problems of cashmere industry in our country. Journal of Gansu Agriculture University, 62-67

Du, Juan. (2010). Unbearable Chinese Cashmere Enterprise Heavy Costs. Chinese Business Times. [Online] Available: http://www.cbt.com.cn/a/xinwenzhongxin/hongguan/2010/1111/13723.html (Nov. 11, 2010).

Geoffrey A. Jehle \& Philip J. Reny. (2002). Advance Microeconomic Theory. Shanghai University of Finance and Economics Press, 268-277.

Inner Mongolia statistical yearbook of 2004-2008. China statistics press.

Liang, Zhe. (2007). The deduction of a decision weight $\pi$ : controversies, questions, and answers. Mathematics in Economics Journal, 321-340

Nie, Biao, Zhao, Feng \& Yu, Jiafeng. (2010). The Impact of the Financial Crisis on Consumer Behavior and the Implications of Retail Revolution. Orient Academic Forum, Sydney Australia 2010. 482-486.

R. Glenn Hubbard. (2000). Money, the financial System and the Economy. Addison-Wesley Publishing Company, Inc. 751-757

Robert L. Wallack. (2008). Cashmere from the Land of Mystery. 28-31. [Online] Available: http://www.aatcc.org 
(May 1, 2008).

Rudiger Dornbusch. (2003). Macroeconomics. Shenyang: Dongbei University of Financial and Economics Press, 167-172.

Wen, Jiandong \& Huang, Hao. (2008). Empirical study of relationship between PPP and exchange rate. Shanghai: China Money, 16-22.

Zhang, Lizhong \& Jia Yushan. (2009). Analysis of Cashmere market and developmental strategies for China's cashmere industry. Journal of Beijing Technology and Business University (Social Science), 117-121.

Table 1. 2003-2007 Inner Mongolia Main Cashmere Products Export

\begin{tabular}{l|c|c|c|c|c|c}
\hline \multicolumn{1}{|c|}{ ITEMS } & $\begin{array}{c}\text { CASHMERE } \\
\text { SWEATER } \\
\text { (unit/kg) }\end{array}$ & $\begin{array}{c}\text { ANNUAL } \\
\text { GROWTH } \\
\text { RATE }(\%)\end{array}$ & $\begin{array}{c}\text { COMBED } \\
\text { CASHMER } \\
\text { RATE(ton) }\end{array}$ & $\begin{array}{c}\text { ANNUAL } \\
\text { GROWTH } \\
(\%)\end{array}$ & $\begin{array}{c}\text { CASHMERE } \\
\text { YARNS } \\
(\mathrm{kg})\end{array}$ & $\begin{array}{c}\text { ANNUAL } \\
\text { GROWTH }\end{array}$ \\
\hline 2003 & 3349662 & & 1383 & & 542204 & RATE (\%) \\
\hline 2004 & 5132327 & 53 & 893 & -35 & 987653 & 82 \\
\hline 2005 & 5974784 & 16 & 1050 & 18 & 650046 & -34 \\
\hline 2006 & 6256319 & 4 & 854 & -19 & 800545 & 23 \\
\hline 2007 & 7323451 & 14 & 422 & -50 & 799858 & -0.0009 \\
\hline
\end{tabular}

The above table shows the Inner Mongolia Main Cashmere Products Export from 2003 to 2007 and the export growth of Inner Mongolia main cashmere products have been gradually decreasing.

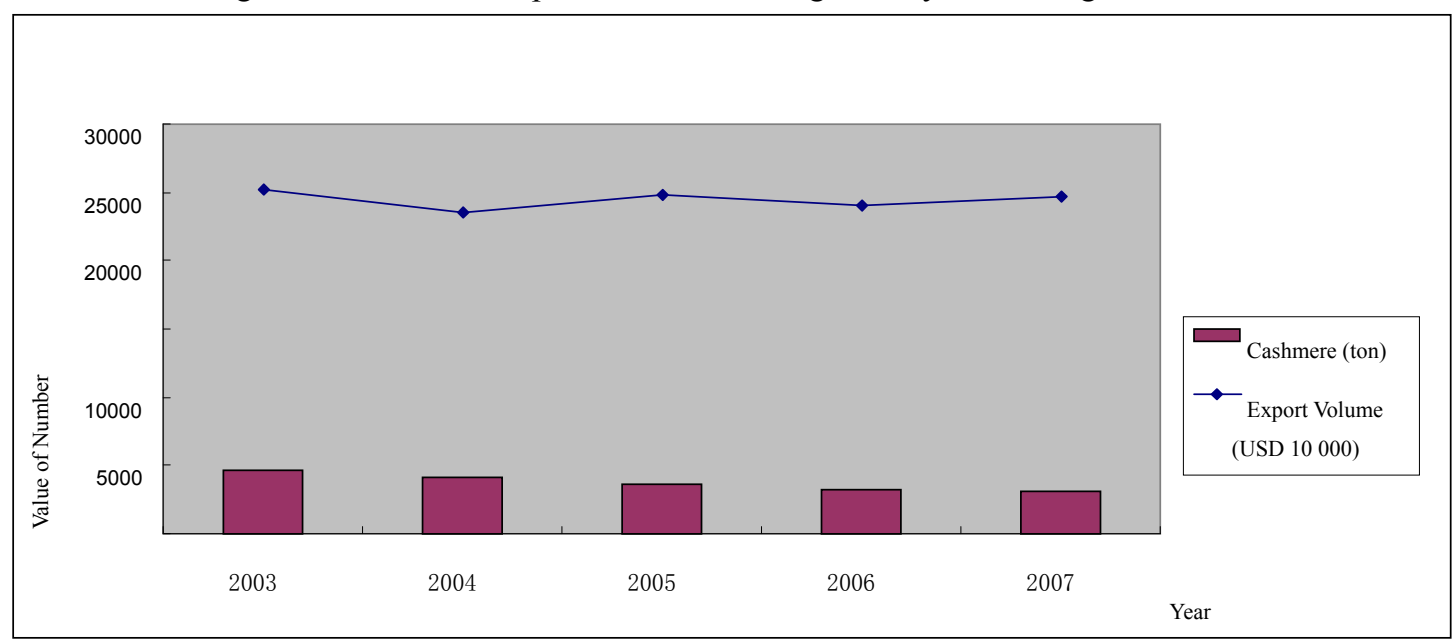

Figure 1. 2003-2008 China Cashmere Export Situation

The volume of exports of China Cashmere decreases from 2003 to 2008 affected by economic crisis.

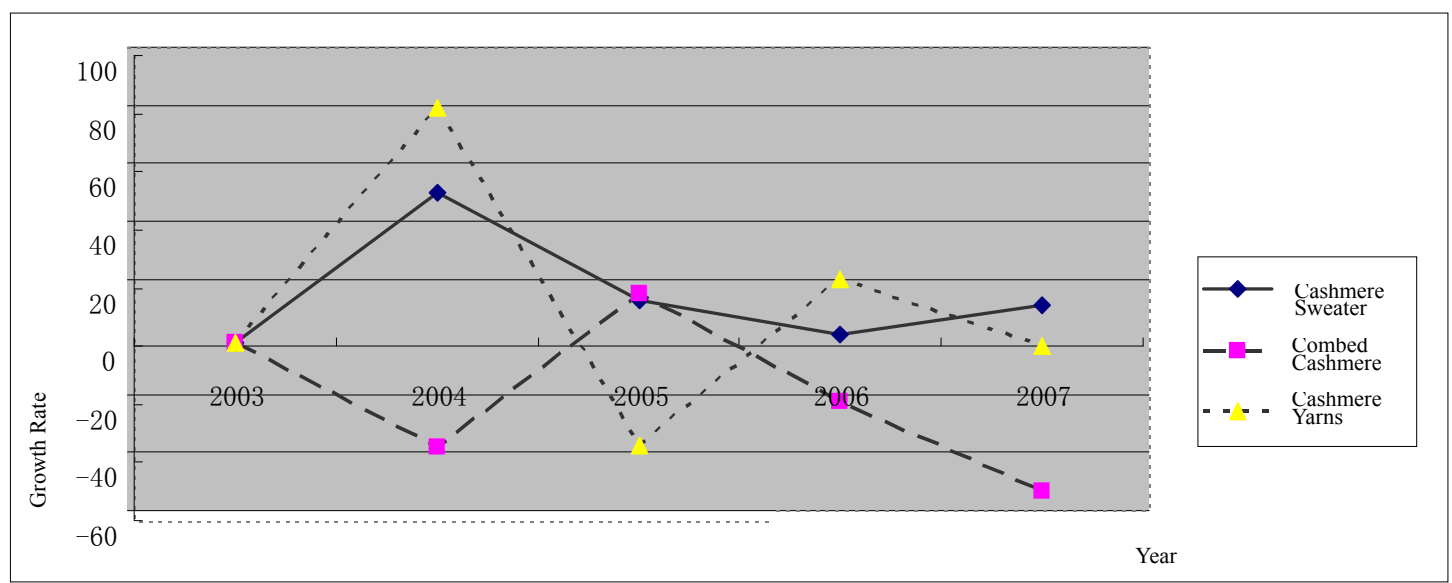

Figure 2. 2003-2007 Variation Tendency of Inner Mongolia

Main Cashmere Products Exports Growth Rate

The export growth rate of Inner Mongolia main cashmere products have been gradually decreasing since 2003 . 